\title{
Prevalence and risk factors of Helicobacter pylori infection in Korea: Nationwide multicenter study over 13 years
}

Seon Hee Lim ${ }^{1 \dagger}$, Jin-Won Kwon ${ }^{2 \dagger}$, Nayoung Kim, ${ }^{3,4^{*}}$, Gwang Ha Kim5, Jung Mook Kang ${ }^{1}$, Min Jung Park', Jeong Yoon Yim', Heung Up Kim ${ }^{6}$, Gwang Ho Baik', Geom Seog Seo ${ }^{8}$, Jeong Eun Shin ${ }^{9}$, Young-Eun Joo ${ }^{10}$, Joo Sung Kim ${ }^{1,4}$ and Hyun Chae Jung ${ }^{4}$

\begin{abstract}
Background: The aim of this study was to evaluate the time trend of seropositivity of Helicobacter pylori (H. pylori) over the period of 13 years in an asymptomatic Korean population, and investigate associated risk factors.

Methods: This cross-sectional nationwide multicentre study surveyed anti-H. pylori lgG antibodies in 19,272 health check-up subjects (aged [greater than and equal to]16 years) in 2011. Risk factors for H. pylori infection were investigated using logistic regression. Seropositivity in asymptomatic subjects without $H$. pylori eradication was compared between the years 1998 and 2005. Birth cohort effects were also evaluated.

Results: After exclusion of subjects with a history of H. pylori eradication therapy $(n=3,712,19.3 \%)$ and gastric symptoms ( $n=4,764,24.7 \%$ ), the seroprevalence of $\mathrm{H}$. pylori infection was $54.4 \%$ in 10,796 subjects. This was significantly lower than the seroprevalence of 59.6\% in 2005 and that of $66.9 \%$ in 1998, and this decrease of seropositivity of $\mathrm{H}$. pylori became widespread across all ages and in most areas of the country. This decreasing trend could be explained by cohort analysis. All younger birth cohorts had a lower seroprevalence of H. pylori than older birth cohorts at the same age. Decreased seroprevalence within the same birth cohorts also accounted for this phenomenon. Clinical risk factors of H. pylori infection were higher cholesterol level ([greater than and equal to] $240 \mathrm{mg} / \mathrm{dl})(\mathrm{OR}=1.33 ; 95 \% \mathrm{Cl}=1.14-1.54)$, male gender, older age, low income, and residence in a rural area.

Conclusions: A decreasing trend of $\mathrm{H}$. pylori seroprevalence due to a birth cohort effect requires further studies on its related human host factors as well as socio-economic and hygienic factors. In addition, the relationship between H. pylori infection and high cholesterol level needs more investigation regarding underlying pathogenesis.
\end{abstract}

Keywords: Helicobacter pylori, Seroprevalence, Epidemiology, Cohort

\section{Background}

Helicobacter pylori (H. pylori), a cause of peptic ulcer disease, gastric adenocarcinoma, and low-grade gastric mucosa associated lymphoid tissue (MALT) lymphoma [1] has been falling due to improved sanitation and better living conditions [2,3]. However, its prevalence is reported to be still high, especially in Asia including

\footnotetext{
* Correspondence: nayoungkim49@empal.com

${ }^{\dagger}$ Equal contributors

${ }^{3}$ Department of Internal Medicine, Seoul National University Bundang

Hospital, Seongnam, Korea

${ }^{4}$ Department of Internal Medicine and Liver Research Institute, Seoul

National University College of Medicine, Seoul, Korea

Full list of author information is available at the end of the article
}

South Korea. From the public health perspective, observation of prevalence trends and confirmation of risk factors for $H$. pylori infection are important to establish health policies to prevent $H$. pylori related diseases.

There are many studies regarding the prevalence and risk factors of $H$. pylori infection, and older age was commonly considered as the main risk factor $[4,5]$. One study mentioned that adults have a continuous risk of $H$. pylori infection, resulting in increased seroprevalence during lifetime as a function of age [6]. However, this does not mean that young people have a higher seroprevalence when they get older, showing that cross sectional presentation does not necessarily give an accurate

\section{Ciomed Central}


picture of lifetime trends. Also, there are limited studies on lifetime trends for $H$. pylori seroprevalence $[7,8]$.

In South Korea, previous study also indicated a decreasing pattern of $H$. pylori infection during a time period between 1998 and 2005 [9]. As Korea is in a dynamic state of progression from a developing country into a developed country, it may be valuable to evaluate the seroprevalence of $H$. pylori in Korea. In accordance with this point of view, the aim of this study was to investigate the trends of seropositivity of $H$. pylori in asymptomatic Korean subjects over 16 years of age together with cohort effects between the years 1998 and 2011, and to find factors related to H. pylori infection.

\section{Methods}

\section{Study population}

This is a cross-sectional nationwide multicentre study of adult subjects aged 16 years or older who visited healthcare centers for routine health check-up between January and December 2011 in South Korea. The subjects were enrolled prospectively in 2011 under a predefined protocol. The institutions participating in this study were healthcare centers located in Seoul and in the seven provinces of South Korea.

Informed consent was obtained from each subject. All subjects were invited to answer the questionnaire which was the same as previous study's [9] under the supervision of a well-trained interviewer. The questionnaire included information regarding demographic data (i.e. age, sex, and residence), socioeconomic data (i.e. monthly income and education level), medical history (such as H. pylori eradication therapy, history of gastric operation, and family history of gastric cancer (GC)), and upper gastrointestinal (GI) symptoms (such as indigestion, bloating, epigastric soreness, regurgitation, or heartburn), that persisted for at least one month within the last 3 years.

Subjects were categorized into 3 education levels: low (middle school graduate or less), middle (high school graduate or university dropout), and high (university graduate or graduate of a postgraduate course). Monthly family income was classed as 3 groups: low household income (< US \$3,000 per month), middle income (US $\$ 3,000$ to 10,000 per month), and high income (> US $\$ 10,000$ per month).

\section{Clinical and laboratory evaluations}

Anthropometric measurements (weight and height) were done by trained nurses using a standardized protocol.

Blood samples were obtained from the antecubital vein in the morning after overnight fasting, and serum samples were separated after centrifugation. Serum cholesterol, triglyceride, and fasting glucose were measured by an automatic analyser, Alisei (Seac, Pomezia, Italy). To compare these results according to seropositivity of $H$. Pylori, we categorized the level of total cholesterol (TC) as normal $(\leq 240 \mathrm{mg} / \mathrm{dl})$ and abnormal $(>240 \mathrm{mg} / \mathrm{dl})$, trigryceride (TG) as $\leq 150 \mathrm{mg} / \mathrm{dl}$ and $>150 \mathrm{mg} / \mathrm{dl}$, and fasting glucose as $\leq 100 \mathrm{mg} / \mathrm{dl}$ and $>100 \mathrm{mg} / \mathrm{dl}$, respectively.

Anti-H. pylori IgG was measured using $H$. pylori-EIAWell in Healthcare System Gangnam Center and Genedia $H$. pylori ELISA at the remaining centers using the same kits as those in the previous studies $[9,10]$. Genedia H. pylori ELISA, developed from Korean $H$. pylori strains showed a sensitivity of $97.8 \%$ and a specificity of 92\% [11]. H. pylori-EIA-Well showed a sensitivity of $95.6 \%$ and a specificity of $97.8 \%$ when Genedia $H$. pylori ELISA was used as the gold standard [9].

\section{Statistical analysis \\ Evaluation of risk factors of each group according to eradication of $\mathrm{H}$. pylori}

Demographic and clinical information were summarized by descriptive statistics. To investigate risk factors for H. pylori seropositivity and influential factors having a history of $H$. pylori eradication, multivariable logistic regression was used. A significance level of $p<0.05$ was used for all analyses.

\section{Comparison of trends of seroprevalence of $H$. pylori in 1998, 2005, and 2011}

Trends of seroprevalence of $H$. pylori were compared using the published data of 1998 [10] and 2005 [9]. For this comparison, study subjects in each time period were restricted to asymptomatic subjects without a history of H. pylori eradication and gastric operation. For statistical comparison of trends of seroprevalence of $H$. pylori in 1998, 2005, and 2011, the Cochrane-Armitage trend test, which is a modified Pearson chi-square test to examine the association between a binary outcome and a variable with multiple categories with order, was conducted.

\section{Analysis of cohort effects}

In addition, the seroprevalence of $H$. pylori by birth cohort group was also drawn. To examine birth cohort effects, we created synthetic cohorts from the successive crosssectional data of 1998, 2005, and 2011. For this analysis, relevant raw data in 1998 and 2005 were obtained from the authors and reconstructed for the analysis of birth cohort. Data from 1998 was considered to be those in 1999 because the successive cross-sectional data should span with same interval. The interval of three cross-sectional data was 6 years. The aggregate birth cohort from 1930 to 1972 was restructured into 8 groups using the standard approach for cohort analysis [12]. In detail, a birth cohort was obtained by subtracting age from year (i.e. Birth cohort of 1974.5 (birth cohort of 1972-77) = Year of $1998-$ Age of 24.5 (22-27 years old)). For example, people aged 22-27 years in 1998 (considered as data in 1999), those 
aged 28-33 years in 2005, and those aged 34-39 years in 2011 were considered to be in the same birth cohort, born between 1972 and 1977. Using this approach for other age groups in each year, eight birth cohorts (1972-77, 1966-71, 1960-65, 1954-59, 1948-53, 1942-47,1936-41,1930-35) had three estimates of $H$. pylori seroprevalence at 6 year intervals for 12 years.

\section{Ethics statement}

The protocol of this study was approved by the main Institutional Review Board of Seoul National University Hospital (IRB No. H-1011-038-339).

\section{Results}

\section{Seroprevalence and eradication history of $H$. pylori in total subjects}

The seroprevalence of $H$. pylori was $52.8 \%(8,216 / 15,560)$ after exclusion of $H$. pylori eradicated history in 19,272 eligible subjects and $54.4 \%(5,882 / 10,796)$ after exclusion of symptomatic subjects (Figure 1 ).

The demographics and clinical characteristics by group are presented in Table 1.

Among the 19,272 subjects, $19.3 \%$ reported a history of eradication therapy for $H$. pylori infection. By logistic regression modeling, the influencing factors for having a history of eradication therapy for $H$. pylori infection were male, older age, higher income, living in Seoul (Capital area), the presence of GI symptom and GC family history (Table 2).

Risk factors for $H$. pylori infection in asymptomatic subjects without a history of $H$. pylori eradication

The risk factors for $H$. pylori infection in asymptomatic subjects without a history of $H$. pylori eradication were significantly associated with gender, age, geographic area, economic status, education level, and cholesterol level (Table 3). Seropositivity of $H$. pylori was significantly lower in females than in males $(\mathrm{OR}=0.79,95 \% \mathrm{CI}=0.71-0.87)$. By age, seroprevalence increased in a nearly linear fashion from 20 to 59 years of age. However, the prevalence remained steady from 60 years of age. Regarding residence, when compared with Seoul, other provinces except for Gyeonggi and Kangwon had a higher risks of H. pylori seropositivity. Subjects with high income and high education level had a lower likelihoods of having H. pylori seropositivity. Subjects with a higher TC level $(\geq 240 \mathrm{mg} / \mathrm{dl})$ had a $30 \%$ higher likelihood of having $H$. pylori seropositivity compared with subjects with a lower TC $(<240 \mathrm{mg} / \mathrm{dl})$ $(\mathrm{OR}=1.33,95 \% \mathrm{CI}=1.14-1.54)$ after adjustments for BMI, age, and income level. However, blood glucose level and TG level did not affect the seropositivity of $H$. pylori infection after adjustment for other variables. Family history of GC and BMI level did not affect the seropositivity of H. pylori.

Comparison of seroprevalence of $H$. pylori among 2011, 2005, and 1998 in asymptomatic subjects without a history of $H$. pylori eradication

Comparison of seroprevalence of $H$. pylori from 1998, 2005 and 2011 was performed, and the data from 1998 and 2005 were investigated by the Korean H. pylori Study Group [10] and our group [9], respectively. The overall seroprevalence of $H$. pylori infection was $54.4 \%$ (95\% CI: $53.5-55.4 \%)$ in 2011 which is significantly decreased from $66.9 \%$ (95\% CI: 65.4-68.6\%) in 1998, and $59.6 \%$ (95\% CI: $58.5-60.7 \%)$ in $2005(\mathrm{p}<0.001)$ (Panel A of Figure 2). There was a statistically significant reduction between 1998 and 2005, and between 2005 and 2011.

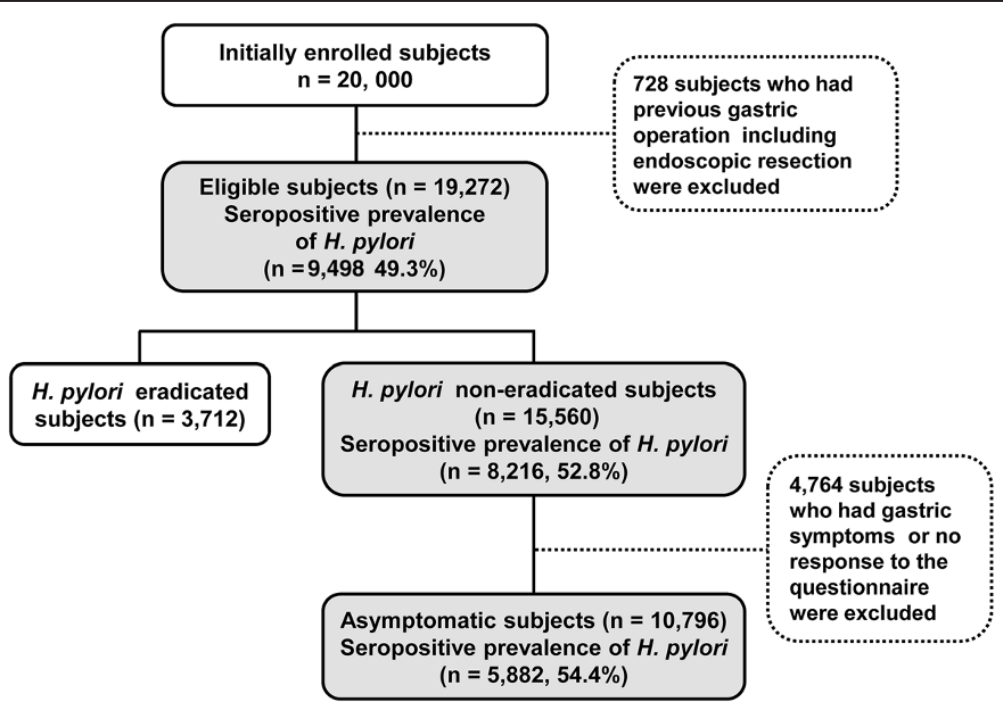

Figure 1 Study flowchart in 2011. 
Table 1 Baseline characteristics of subjects

\begin{tabular}{|c|c|c|c|c|c|c|c|}
\hline & & \multicolumn{2}{|c|}{$\begin{array}{c}\text { Subjects without GI } \\
\text { operation history }\end{array}$} & \multicolumn{2}{|c|}{$\begin{array}{l}\text { Subjects without history } \\
\text { of } H \text {. pylori eradication }\end{array}$} & \multicolumn{2}{|c|}{$\begin{array}{l}\text { Asymptomatic subjects without } \\
\text { history of } H \text {. pylori eradication }\end{array}$} \\
\hline & & $\mathrm{n}$ & $\overline{(\%)}$ & $\mathrm{n}$ & $(\%)$ & $n$ & (\%) \\
\hline Total & & 19,272 & $(100.0)$ & 15,560 & $(100.0)$ & 10,796 & $(100.0)$ \\
\hline \multirow[t]{3}{*}{ Sex } & Male & 10,557 & $(54.8)$ & 8,311 & (53.4) & 6,085 & $(56.4)$ \\
\hline & Female & 8,715 & $(45.2)$ & 7,249 & $(46.6)$ & 4,711 & (43.6) \\
\hline & Subtotal & 19,272 & $(100.0)$ & 15,560 & $(100.0)$ & 10,796 & $(100.0)$ \\
\hline \multirow[t]{8}{*}{ Age (years) } & $16-19$ & 34 & $(0.2)$ & 33 & $(0.2)$ & 17 & $(0.2)$ \\
\hline & $20-29$ & 798 & (4.1) & 777 & (5.0) & 421 & (3.9) \\
\hline & $30-39$ & 2,853 & $(14.8)$ & 2,607 & $(16.8)$ & 1,659 & $(15.4)$ \\
\hline & $40-49$ & 5,087 & (26.4) & 4,198 & $(27.0)$ & 2,913 & $(27.0)$ \\
\hline & $50-59$ & 6,176 & (32.0) & 4,709 & (30.3) & 3,403 & (31.5) \\
\hline & $60-69$ & 3,358 & $(17.4)$ & 2,493 & $(16.0)$ & 1,840 & $(17.0)$ \\
\hline & $\geq 70$ & 966 & $(5.0)$ & 743 & $(4.8)$ & 543 & (5.0) \\
\hline & Subtotal & 19,272 & $(100.0)$ & 15,560 & $(100.0)$ & 10,796 & $(100.0)$ \\
\hline \multirow[t]{8}{*}{ Geographic area } & Seoul & 10,755 & (55.8) & 8,515 & $(54.8)$ & 5,829 & $(54.0)$ \\
\hline & Gyeonggi & 3,025 & (15.7) & 2,403 & $(15.5)$ & 1,683 & (15.6) \\
\hline & Chungcheong & 863 & $(4.5)$ & 740 & $(4.8)$ & 536 & $(5.0)$ \\
\hline & Kyungsang & 1,630 & (8.5) & 1,313 & (8.4) & 914 & $(8.5)$ \\
\hline & Cholla & 1,807 & (9.4) & 1,553 & $(10.0)$ & 1,194 & $(11.1)$ \\
\hline & Kangwon & 588 & (3.1) & 466 & (3.0) & 331 & (3.1) \\
\hline & Jeju & 589 & (3.1) & 555 & (3.6) & 299 & $(2.8)$ \\
\hline & $\left.\overline{\text { Subtotal }}\right|^{*}$ & 19,257 & $(100.0)$ & 15,545 & $(100.0)$ & 10,786 & $(100.0)$ \\
\hline \multirow[t]{4}{*}{ Household income ${ }^{* *}$} & low & 2,114 & $(12.5)$ & 1,838 & (13.5) & 1,247 & (13.2) \\
\hline & medium & 11,049 & $(65.2)$ & 8,843 & $(65.1)$ & 6,197 & (65.6) \\
\hline & high & 3,781 & (22.3) & 2,910 & $(21.4)$ & 2,005 & $(21.2)$ \\
\hline & Subtotal $^{*}$ & 16,944 & $(100.0)$ & 13,591 & $(100.0)$ & 9,449 & $(100.0)$ \\
\hline \multirow[t]{4}{*}{ Education level $^{* * *}$} & low & 1,743 & (9.5) & 1,458 & (9.9) & 984 & (9.7) \\
\hline & medium & 3,667 & (20.0) & 3,004 & (20.4) & 1,981 & (19.4) \\
\hline & high & 12,928 & $(70.5)$ & 10,250 & $(69.7)$ & 7,223 & $(70.9)$ \\
\hline & Subtotal* & 18,338 & $(100.0)$ & 14,712 & $(100.0)$ & 10,188 & $(100.0)$ \\
\hline \multirow[t]{5}{*}{ Body mass index $\left(\mathrm{kg} / \mathrm{m}^{2}\right)$} & $<18.5$ & 840 & $(4.4)$ & 736 & (4.8) & 412 & (3.9) \\
\hline & $18.5-<23.0$ & 7,696 & $(40.6)$ & 6,245 & $(40.7)$ & 4,237 & (39.8) \\
\hline & $23.0-<25.0$ & 4,818 & $(25.4)$ & 3,821 & (24.9) & 2,759 & $(25.9)$ \\
\hline & $\geq 25.0$ & 5,625 & (29.6) & 4,530 & $(29.5)$ & 3,249 & (30.5) \\
\hline & Subtotal $^{*}$ & 18,979 & $(100.0)$ & 15,332 & $(100.0)$ & 10,657 & $(100.0)$ \\
\hline \multirow[t]{3}{*}{ Cholesterol (mg/dl) } & $<240$ & 16,671 & $(90.5)$ & 13,417 & $(90.4)$ & 9,228 & $(90.1)$ \\
\hline & $\geq 240$ & 1,755 & $(9.5)$ & 1,428 & (9.6) & 1,013 & (9.9) \\
\hline & Subtotal $^{*}$ & 18,426 & $(100.0)$ & 14,845 & $(100.0)$ & 10,241 & $(100.0)$ \\
\hline \multirow[t]{3}{*}{$\mathrm{TG}(\mathrm{mg} / \mathrm{dl})$} & $<150$ & 14,651 & $(79.7)$ & 11,873 & $(80.1)$ & 8,118 & $(79.4)$ \\
\hline & $\geq 150$ & 3,736 & (20.3) & 2,941 & (19.9) & 2,102 & (20.6) \\
\hline & Subtotal* & 18,387 & $(100.0)$ & 14,814 & $(100.0)$ & 10,220 & $(100.0)$ \\
\hline \multirow[t]{4}{*}{ Glucose (mg/dl) } & $<100$ & 12,999 & $(70.7)$ & 10,667 & $(72.0)$ & 7,206 & $(70.5)$ \\
\hline & $100-<126$ & 4,438 & $(24.1)$ & 3,399 & $(22.9)$ & 2,459 & $(24.1)$ \\
\hline & $\geq 126$ & 955 & $(5.2)$ & 747 & $(5.0)$ & 555 & $(5.4)$ \\
\hline & Subtotal* & 18,392 & $(100.0)$ & 14,813 & $(100.0)$ & 10,220 & $(100.0)$ \\
\hline
\end{tabular}


Table 1 Baseline characteristics of subjects (Continued)

\begin{tabular}{llrrrrrr}
\hline Family history of gastric cancer & No & 16,470 & $(86.6)$ & 13,418 & $(87.5)$ & 9,473 & $(88.2)$ \\
\cline { 2 - 7 } & Yes & 2,556 & $(13.4)$ & 1,910 & $(12.5)$ & 1,270 & $(11.8)$ \\
\cline { 2 - 7 } & Subtotal* & 19,026 & $(100.0)$ & 15,328 & $(100.0)$ & 10,743 & $(100.0)$ \\
\hline \multirow{2}{*}{ Gl symptoms } & No & 13,121 & $(68.8)$ & 10,796 & $(70.3)$ & \\
\cline { 2 - 7 } & Yes & 5,954 & $(31.2)$ & 4,568 & $(29.7)$ & $(100.0)$ \\
\cline { 2 - 7 } & Subtotal* & 19,075 & $(100.0)$ & 15,364 & & \\
\hline
\end{tabular}

"Subjects with missing values were excluded.

${ }^{* *}$ Household income was classified as low (less than US $\$ 3,000$ ), medium (US $\$ 3,000$ to 10,000 ), or high (more than US $\$ 10,000$ ).

${ }^{* * *}$ Education level was classified as low (middle school graduates or less), middle (high school graduates or university dropouts),

or high (university graduates or graduates of a postgraduate course).

Gl gastrointestinal.

According to geographic area, the seroprevalence showed a significant downward trend in most of areas over time except in Kyungsang and Kangwon. (Panel B of Figure 2).

The seroprevalence of $\mathrm{H}$. pylori and $95 \% \mathrm{CI}$ at intervals of 10 years of age in 1998, 2005, and 2011 were plotted in
Panel $\mathrm{C}$ of Figure 2. The seroprevalence of $H$. pylori was decreased in the all age groups over time with statistical significance from 1998 to 2011. A steep decreasing pattern was observed for subjects under 40 years of age between 1998 and 2005. However, when the time period was

Table 2 Multivariate analysis of factors affecting $H$. pylori eradication therapy

\begin{tabular}{|c|c|c|c|c|c|c|c|}
\hline & & \multirow[t]{2}{*}{ Total } & \multicolumn{2}{|c|}{ Subjects with history of $H$. pylori eradication } & \multirow[t]{2}{*}{ Odds ratio } & \multicolumn{2}{|c|}{$95 \% \mathrm{Cl}$} \\
\hline & & & $\mathbf{n}$ & $\%$ & & & \\
\hline Total & & 19,272 & 3,712 & 19.3 & & & \\
\hline \multirow[t]{2}{*}{ Sex } & Male & 10,557 & 2,246 & 21.3 & Ref & & \\
\hline & Female & 8,715 & 1,466 & 16.8 & 0.77 & 0.71 & 0.84 \\
\hline \multirow[t]{7}{*}{ Age (years) } & $16-19$ & 34 & 1 & 2.9 & 2.27 & 0.28 & 18.21 \\
\hline & $20-29$ & 798 & 21 & 2.6 & Ref & & \\
\hline & 30-39 & 2,853 & 246 & 8.6 & 4.22 & 2.44 & 7.31 \\
\hline & $40-49$ & 5,087 & 889 & 17.5 & 9.32 & 5.44 & 15.94 \\
\hline & $50-59$ & 6,176 & 1,467 & 23.8 & 14.33 & 8.39 & 24.48 \\
\hline & $60-69$ & 3,358 & 865 & 25.8 & 16.91 & 9.87 & 28.97 \\
\hline & $\geq 70$ & 966 & 223 & 23.1 & 16.73 & 9.58 & 29.20 \\
\hline \multirow[t]{7}{*}{ Geographic area } & Seoul & 10,755 & 2,240 & 20.8 & Ref & & \\
\hline & Gyeonggi & 3,025 & 622 & 20.6 & 0.97 & 0.87 & 1.08 \\
\hline & Chungcheong & 863 & 123 & 14.3 & 0.76 & 0.61 & 0.94 \\
\hline & Kyungsang & 1,630 & 317 & 19.4 & 0.85 & 0.74 & 0.99 \\
\hline & Cholla & 1,807 & 254 & 14.1 & 0.68 & 0.58 & 0.80 \\
\hline & Kangwon & 588 & 122 & 20.7 & 1.30 & 1.04 & 1.64 \\
\hline & Jeju & 589 & 34 & 5.8 & 0.27 & 0.19 & 0.39 \\
\hline \multirow[t]{3}{*}{ Household income* } & Low & 2,114 & 276 & 13.1 & 0.70 & 0.58 & 0.83 \\
\hline & Medium & 11,049 & 2,206 & 20.0 & 0.96 & 0.87 & 1.05 \\
\hline & High & 3,781 & 871 & 23.0 & Ref & & \\
\hline \multirow[t]{3}{*}{ Education level** } & Low & 1,743 & 285 & 16.4 & 0.70 & 0.59 & 0.84 \\
\hline & Medium & 3,667 & 663 & 18.1 & 0.87 & 0.78 & 0.97 \\
\hline & High & 12,928 & 2,678 & 20.7 & Ref & & \\
\hline \multirow[t]{2}{*}{ Gl symptoms } & No & 13,121 & 2,325 & 17.7 & Ref & & \\
\hline & Yes & 5,954 & 1,386 & 23.3 & 1.60 & 1.47 & 1.73 \\
\hline \multirow[t]{2}{*}{ Family history of gastric cancer } & No & 16,470 & 3,052 & 18.5 & Ref & & \\
\hline & Yes & 2,556 & 646 & 25.3 & 1.34 & 1.21 & 1.49 \\
\hline
\end{tabular}

***, Gl, same as those of Table 1.

$\mathrm{Cl}$ confidence Interval, Ref reference.

Total subject number of multivariable logistic regression was 16,770 . 
Table 3 Risk factors for $H$. pylori seropositivity in asymptomatic subjects without a history of $\boldsymbol{H}$. pylori eradication and gastric operation (Multivariable logistic regression)

\begin{tabular}{|c|c|c|c|c|c|c|c|}
\hline & & \multirow[t]{2}{*}{ Total } & \multicolumn{5}{|c|}{ H. pylori Seropositivity } \\
\hline & & & $\mathbf{N}$ & $\%$ & Odds ratio & & \\
\hline \multirow[t]{2}{*}{ Sex } & Male & 6,085 & 3,472 & 57.1 & Ref & & \\
\hline & Female & 4,711 & 2,410 & 51.2 & 0.79 & 0.71 & 0.87 \\
\hline \multirow[t]{7}{*}{ Age (years) } & $16-19$ & 17 & 2 & 11.8 & 0.55 & 0.11 & 2.68 \\
\hline & $20-29$ & 421 & 111 & 26.4 & Ref & & \\
\hline & $30-39$ & 1,659 & 698 & 42.1 & 1.55 & 1.18 & 2.04 \\
\hline & $40-49$ & 2,913 & 1,531 & 52.6 & 2.39 & 1.83 & 3.11 \\
\hline & $50-59$ & 3,403 & 2,088 & 61.4 & 3.52 & 2.70 & 4.60 \\
\hline & $60-69$ & 1,840 & 1,134 & 61.6 & 3.57 & 2.70 & 4.71 \\
\hline & $\geq 70$ & 543 & 318 & 58.6 & 3.11 & 2.24 & 4.31 \\
\hline \multirow[t]{7}{*}{ Geographic area } & Seoul & 5,829 & 2,917 & 50.0 & Ref & & \\
\hline & Gyeonggi & 1,683 & 898 & 53.4 & 1.07 & 0.95 & 1.21 \\
\hline & Chungcheong & 536 & 297 & 55.4 & 1.29 & 1.05 & 1.58 \\
\hline & Kyungsang & 914 & 595 & 65.1 & 1.29 & 1.06 & 1.57 \\
\hline & Cholla & 1,194 & 790 & 66.2 & 1.66 & 1.41 & 1.96 \\
\hline & Kangwon & 331 & 200 & 60.4 & 1.19 & 0.92 & 1.54 \\
\hline & Jeju & 299 & 176 & 58.9 & 1.36 & 1.05 & 1.77 \\
\hline \multirow[t]{3}{*}{ Household Income* } & Low & 1,247 & 785 & 63.0 & 1.21 & 1.00 & 1.45 \\
\hline & Medium & 6,197 & 3,416 & 55.1 & 1.07 & 0.96 & 1.19 \\
\hline & High & 2,005 & 1,042 & 52.0 & Ref & & \\
\hline \multirow[t]{3}{*}{ Education** } & Low & 984 & 629 & 63.9 & 1.01 & 0.84 & 1.23 \\
\hline & Medium & 1,981 & 1,165 & 58.8 & 1.13 & 1.00 & 1.28 \\
\hline & High & 7,223 & 3,779 & 52.3 & Ref & & \\
\hline \multirow[t]{4}{*}{ Body Mass Index $\left(\mathrm{kg} / \mathrm{m}^{2}\right)$} & $<18.5$ & 412 & 180 & 43.7 & 1.03 & 0.81 & 1.31 \\
\hline & $18.5-<23.0$ & 4,237 & 2,224 & 52.5 & Ref & & \\
\hline & $23.0-<25.0$ & 2,759 & 1,565 & 56.7 & 0.98 & 0.88 & 1.10 \\
\hline & $\geq 25$ & 3,249 & 1,830 & 56.3 & 0.95 & 0.84 & 1.06 \\
\hline \multirow[t]{2}{*}{ Cholesterol (mg/dl) } & $<240$ & 9,228 & 4,882 & 52.9 & Ref & & \\
\hline & $\geq 240$ & 1,013 & 624 & 61.6 & 1.33 & 1.14 & 1.54 \\
\hline \multirow[t]{2}{*}{ Triglyceride (mg/dl) } & $<150$ & 8,118 & 4,316 & 53.2 & Ref & & \\
\hline & $\geq 150$ & 2,102 & 1,179 & 56.1 & 0.98 & 0.87 & 1.10 \\
\hline \multirow[t]{3}{*}{ Glucose (mg/dl) } & $<100$ & 7,206 & 3,786 & 52.5 & Ref & & \\
\hline & $100-<126$ & 2,459 & 1,378 & 56.0 & 0.93 & 0.84 & 1.04 \\
\hline & $\geq 126$ & 555 & 328 & 59.1 & 0.98 & 0.80 & 1.19 \\
\hline \multirow[t]{2}{*}{ Family history of gastric cancer } & No & 9,473 & 5,152 & 54.4 & Ref & & \\
\hline & Yes & 1,270 & 700 & 55.1 & 0.96 & 0.84 & 1.09 \\
\hline
\end{tabular}

*,**, Gl, Cl, Ref, same as those of Table 2.

Total subject number of multivariable logistic regression was 8,688 .

extended to 2011, the declining trend was more prominent in older age groups, resulting in an overall decrease for all age groups.

\section{The birth cohort effects}

To observe lifetime trends, the seroprevalence of $H$. pylori of categorized birth cohorts against age were plotted as shown in Figure 3. Each line connects the values for the same cohort-group in different age groups. For example, a line first represents a birth cohort of 197277 in all graphs. At the same age of 28-33 years (mean 30.5 years old), a younger birth cohort of 1972-77 had a lower seroprevalence of $H$. pylori when compared with a older birth cohort of 1966-71. Likewise, all younger birth cohorts at the same age had a lower seroprevalence of $H$. pylori compared with older birth cohorts. Within 


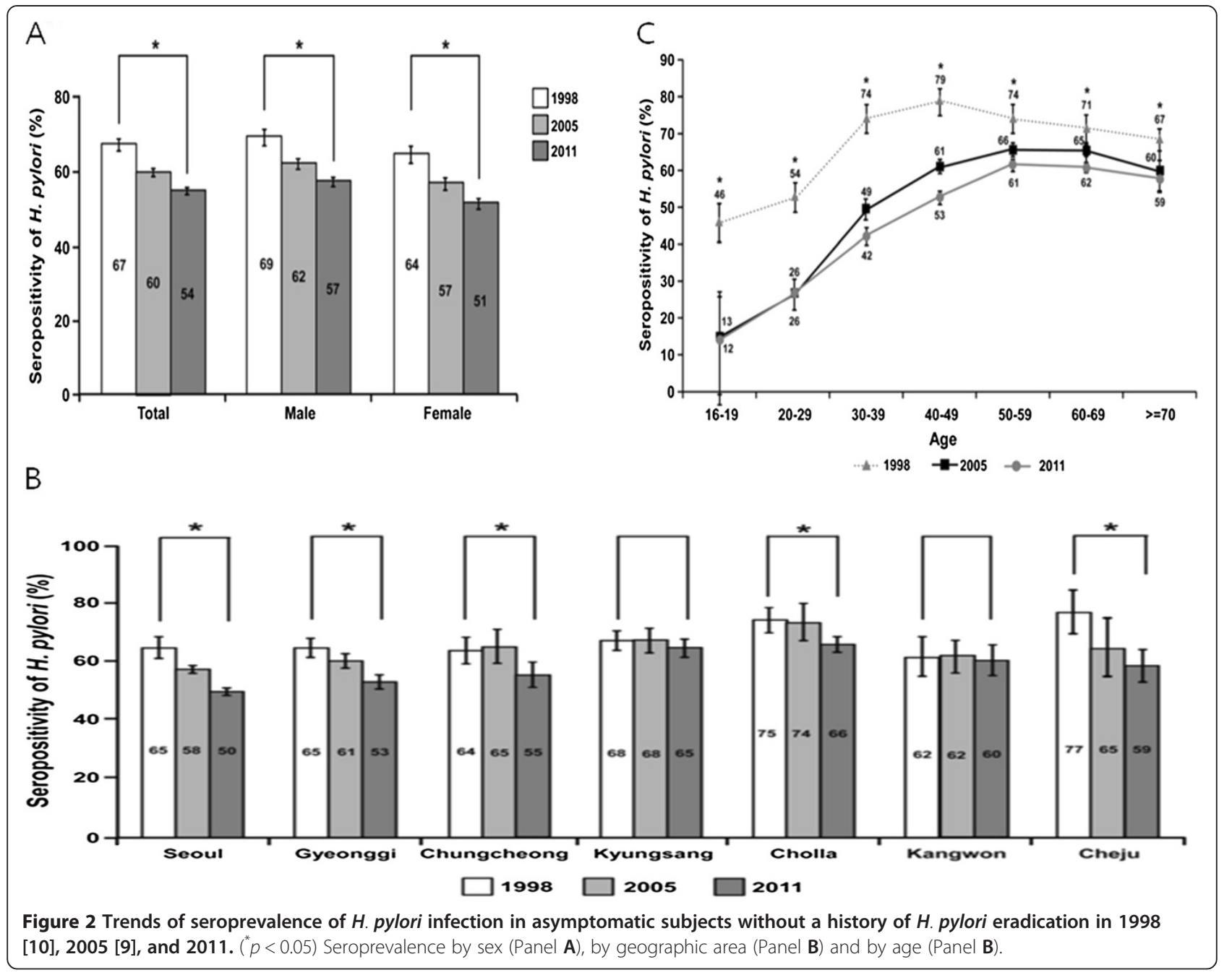

the same birth cohort, most birth cohorts had decreasing pattern of seropositivity of $H$. pylori except for a birth cohort of 1972-1977. This birth cohort showed a decreasing pattern from 22-27 to 28-33 years of age, but it showed a very slight increase (from $41 \%$ to $43 \%$ ) from 28-33 to 34-39 years of age.

\section{Discussion}

The decreasing trend (from $66.9 \%$ to $54.4 \%$ ) of seroprevalence of $H$. pylori over 13 years was explained by birth cohort analysis, and a relationship between $H$. pylori infection and high cholesterol level was found in this large cohort.

A drop in the seroprevalence of $H$. pylori infection has been observed in previous studies [2,3,13]. This trend was most often explained by a combination of various factors including rapid economic growth, improved sanitation, and widespread use of antibiotics and proton pump inhibitors [2,3]. Similarly, the overall seroprevalence of $H$. pylori significantly decreased in the last survey of the Korean population in 2005 [9] compared with that in 1998 [10], but the declining trend was different depending on the age groups and areas. Although the drop in $H$. pylori infection was bigger in younger age groups of subjects 40 years old or less for seven years from 1998 to 2005, the difference of seroprevalence in older groups during same periods was smaller, as shown in the upper two lines of figure 2C. In addition, regarding areas, only subjects who lived in Seoul (capital) and Gyeonggi province which surrounds the capital, showed a clear declining trend during the same periods, but not in all districts in previous study [9]. Furthermore, subjects who lived in Chungcheong province showed a slight increase between 1998 and 2005.

However, when we extended the time period to 2011 in this study, this decreasing trend was more prominent for all ages over 13 years. Similarly, a Japanese study of seropositivity trends of $H$. pylori over a period of 10 years from 1992 to 2002-2006 also found declining trends of seropositivity for all age groups [13]. Regarding province, there was no increasing pattern in any 


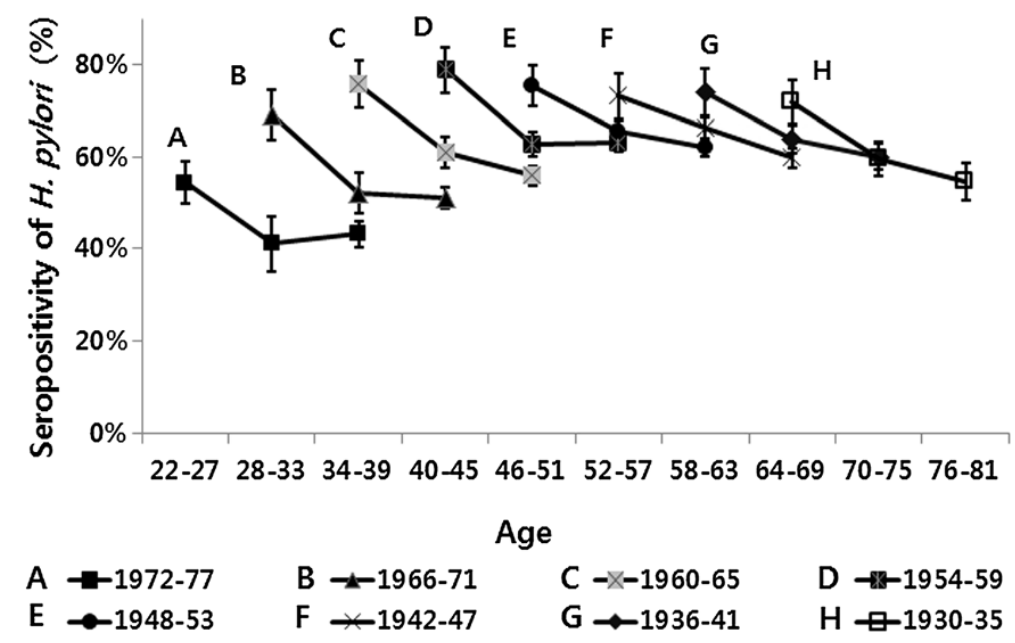

Figure 3 Seroprevalence of $H$. pylori infection in asymptomatic subjects without a history of $H$. pylori eradication in birth cohort against age. Each line connects the values for the same cohort-group in different age group. For example, the first line shows the seroprevalence of $\mathrm{H}$. pylori in a birth cohort of 1972-77 for ages of 22-39 years, and the second line shows the seroprevalence of $H$. pylori in a birth cohort of 1966-71 for ages of 28-45 years. All younger birth cohorts at the same age have a lower seroprevalence of $H$. pylori than older birth cohorts.

province, and a statistically significant decreasing trend was observed in all provinces except two provinces, Kyungsang and Kangwon areas.

We also analyzed birth cohort effects. In the cross sectional study, the prevalence of $H$. pylori infection increased till $40-49$ years of age, after which it remained steady. When we graphically drew the prevalence in $H$. pylori infection by birth cohort to differentiate the increase of infection during aging, the seroprevalence was lower in younger birth cohort (i.e. people who were born later) than the older birth cohort (people who were born earlier) at the same age, showing a clear cohort effect in subjects up to $40-45$ years of age. This phenomenon could be explained by continuous influx of younger birth cohorts [7]. A similar birth cohort effect for $H$. pylori infection was observed in Western studies $[2,3,7,8]$. In addition, $H$. pylori infection in adults is mostly acquired by the age of 15 years $[7,8]$. One study which followed children (1-3 years old) for 21 years indicated that the annual seroconversion rate had a highest risk at the age of 4-5 years, and newly acquired $H$. pylori infections mostly occurred by the age of 10 years [14]. However, there is a doubt whether only a birth cohort effect could explain this pattern. That is, one study in Canada mentioned that an increasing pattern of $H$. pylori infection with advancing age may be due to the continuous risk of infection in adults rather than cohort effects [6]. The decrease of $H$. pylori seroprevalence with advancing age within the same birth cohort in our study strongly suggests that aging is not likely to raise risk of $H$. pylori infection. There was a decreasing effect with advancing age within the same birth cohorts. This might have occurred as a result of cases taking antibiotics or proton pump inhibitors even without formal eradication therapy of H. pylori [15].

There have been several studies regarding risk factors of $H$. pylori infection $[9,14,16-18]$, but their results are still unclear, except socioeconomic status as the risk factors. Our results also showed that lower social economic status is associated with the risk of $H$. pylori infection in a cross sectional analysis. Furthermore, subjects with lower social economic status had a lower likelihood of taking $H$. pylori eradication therapy in the present study. Interestingly, our study showed a relationship between cholesterol level and seropositivity of $H$. pylori. Subjects who had a TC level of $\geq 240 \mathrm{mg} / \mathrm{dl}$ were 1.3 times more likely to be seropositive for $H$. pylori. In frequency analysis, higher levels of TG and glucose as well as TC were also associated with $H$. pylori infection, but after adjusting for demographic variables, clinical information, and socioeconomic status(i.e. age, BMI, income and etc.), only TC among metabolic parameters was related to $H$. pylori infection. So far, the results regarding the relationship between lipid parameters such as TC, TG and low-density lipoprotein cholesterol (LDL-C) levels and H. pylori seropositivity have not been consistent. Some studies [19-21] reported no relationship, but several studies reported higher atherogenic lipid parameter levels in $H$. pylori seropositive subjects in comparison with seronegative ones [22-24] as seen in the present study. Our study results could be convincing for demonstrating the effect of $H$. pylori 
infection on atherosclerotic disease because the positive relationship between $\mathrm{TC}$ and $H$. pylori seropositivity was persistent even after adjustment for BMI and age in a large cohort. The mechanism of how $H$. pylori infection modifies the serum lipid profiles is still not clear, but a plausible explanation is that systemic inflammatory response to the bacterium induces changes in lipid and lipoprotein metabolism [25]. That is, chronic H. pylori infection has been postulated to shift the lipid profile toward an atherogenic direction via the action of proinflammatory cytokines, such as interleukins 1 and 6 , interferon-alpha, and tumor necrosis factor-alpha. These cytokines are capable of affecting lipid metabolism in various ways, including activation of adipose tissue lipoprotein lipase, stimulation of hepatic fatty acid synthesis, influencing lipolysis and the increasing hepatic HMG-CoA reductase activity [26,27]. Thus, $H$. pylori infection could play a role in the atherosclerotic process and may be a reliable indicator for the assessment of cardiovascular disease risk.

There are several limitations which should be acknowledged in this study. First, the relationship between $H$. pylori infection and its risk factors in the cross sectional study could not be proven conclusively. However, this is an unavoidable limitation in the cross sectional study. Second, we compared the time trends of seroprevalence of $H$. pylori using two previous studies $[9,10]$. However, the responsible author (N.K.) did play main role in these previous studies, and the population in 2011 study was restricted to have comparability of $H$. pylori seroprevalence. In other words, the subjects in 2011 study were restricted to asymptomatic people without a history of $H$. pylori eradication and GI operation. Moreover, this study was carried out nationwide, so our findings represent a national trend, not a local phenomenon. Nonetheless, the study subjects in 1998 involved a relatively lower population from Seoul and Gyeonggi, (capital city and its near city) compared with the population in 2005 and 2011. Generally people in capital cities have higher socioeconomic conditions than those living in other areas. It may account for much higher seroprevalence in 1998 compared with $2005 / 2011$. However, the change of seroprevalence by the strata (e.g. age, sex, region, etc.) over time periods may indicate that our overall result is not much influenced by a different proportion of subjects from provinces. Third, for the generation of synthetic cohort, cross-sectional data should have the same interval. However, our data did not have the same interval as the previous data. This is the reason why we considered the data from 1998 as equivalent to those from 1999. This intentional modification could have caused bias, but we think that the bias may be negligible because H.pylori seroprevalence was not changed much by one-year.

\section{Conclusion}

In conclusion, we confirmed that the seropositivity of $H$. pylori declined across all age groups from 1998 to 2011 using nationwide data, an effect which originated from birth cohort effects and continuous risk reduction of $H$. pylori infection during one's life time. In addition, we found that high TC level as well as lower social economic status had a relationship with $H$. pylori infection. These results may suggest the importance of management of $H$. pylori infection in younger age and the effect of $H$. pylori infection on atherosclerosis.

\section{Abbreviations}

GC: Gastric cancer; Gl: Gastrointestinal; H. pylori: Helicobacter pylori; TG: Triglyceride; TC: Total cholesterol.

\section{Competing interests}

All authors declare that they have no conflict of interest.

\section{Authors' contributions}

SHL carried out the acquisition of data, analysis and interpretation of data, and drafting of the manuscript; JK carried out statistical analysis, interpretation of data, and drafting of the manuscript; NK carried out study concept and design, critical revision of the manuscript for important intellectual content and study supervision as a corresponder; GHK participated in acquisition of the data of southeastern part of Korea; JMK participated in design of the study and acquisition of data; MJP participated in acquisition of data; JYY participated in acquisition of data and study concept; HUK participated in acquisition of the data of southernmost part of Korea; GHB participated in acquisition of the data of northeastern part of Korea; GSS participated in acquisition of the data of western part of Korea; JES participated in acquisition of the data of middle upcountry of Korea; YEJ participated in acquisition of the data of southwestern part of Korea ;JSK participated in technical or material support and study supervision ; HCJ participated in study supervision and provided general support. All authors read and approved the final manuscript.

\section{Acknowledgments}

This work was supported by the National Research Foundation of Korea (NRF) grant for the Global Core Research Center (GCRC) funded by the Korea government (MSIP) (No. 2011-0030001)

\section{Author details}

${ }^{1}$ Seoul National University Hospital, Healthcare System Gangnam Center, Healthcare Research Institute, Seoul, Korea. ${ }^{2}$ College of Pharmacy, Kyungpook National University, Daegu, Korea. ${ }^{3}$ Department of Internal Medicine, Seoul National University Bundang Hospital, Seongnam, Korea. ${ }^{4}$ Department of Internal Medicine and Liver Research Institute, Seoul National University College of Medicine, Seoul, Korea. ${ }^{5}$ Department of Internal Medicine, Pusan National University School of Medicine, Busan, Korea. ${ }^{6}$ Department of Internal Medicine, School of Medicine, Jeju National University, Jeju, Korea. ${ }^{7}$ Department of Internal Medicine, Hallym University College of Medicine, Chuncheon, Korea. ${ }^{8}$ Department of Internal Medicine, Wonkwang University Hospital, Iksan, Korea. ${ }^{9}$ Department of Internal medicine, Dankook University College of Medicine, Chonan, Korea. ${ }^{10}$ Department of Internal Medicine, Chonnam National University Medical School, Gwangju, Korea.

Received: 14 January 2013 Accepted: 21 June 2013

Published: 24 June 2013

\section{References}

1. Egan BJ, Holmes K, O'Connor HJ, O'Morain CA: Helicobacter pylori gastritis, the unifying concept for gastric diseases. Helicobacter 2007, 12(Suppl 2):39-44.

2. Parsonnet J: The incidence of Helicobacter pylori infection. Aliment Pharmacol Ther 1995, 9(Suppl 2):45-51.

3. Roosendaal R, Kuipers EJ, Buitenwerf J, Meuwissen SG, van Kamp GJ, Vandenbroucke-Grauls CM: Helicobacter pylori and the birth cohort effect: 
evidence of a continuous decrease of infection rates in childhood. Am J Gastroenterol 1997, 92:1480-1482.

4. Taylor DN, Blaser MJ: The epidemiology of Helicobacter pylori infection. Epidemiol Rev 1991, 13:42-59.

5. Graham DY, Malaty HM, Evans DG, Evans DJ Jr, Klein PD, Adam E: Epidemiology of Helicobacter pylori in an asymptomatic population in the United States. Effect of age, race, and socioeconomic status. Gastroenterology 1991, 100:1495-1501.

6. van Zanten SJ V, Pollak PT, Best LM, Bezanson GS, Marrie T: Increasing prevalence of Helicobacter pylori infection with age: continuous risk of infection in adults rather than cohort effect. J Infect Dis 1994, 169:434-437.

7. Banatvala N, Mayo K, Megraud F, Jennings R, Deeks JJ, Feldman RA: The cohort effect and Helicobacter pylori. J Infect Dis 1993, 168:219-221.

8. Kosunen TU, Aromaa A, Knekt P, Salomaa A, Rautelin H, Lohi P, Heinonen OP: Helicobacter antibodies in 1973 and 1994 in the adult population of Vammala, Finland. Epidemiol Infect 1997, 119:29-34.

9. Yim JY, Kim N, Choi SH, Kim YS, Cho KR, Kim SS, Seo KS, Kim HU, Baik GH, Sin CS, Cho SH, Oh BH: Seroprevalence of Helicobacter pylori in South Korea. Helicobacter 2007, 12:333-340.

10. Kim JH, Kim HY, Kim N, Kim SW, Kim JG, Kim JJ, Roe IH SJK, Sim JG, Ahn H, Yoon BC, Lee SW, Lee YC, Chung IS, Jung HY, Hong WS, Choi KW: Seroepidemiological study of Helicobacter pylori infection in asymptomatic people in South Korea. J Gastroenterol Hepatol 2001, 16:969-975

11. Kim SY, Ahn JS, Ha YJ, Doh HJ, Jang MH, Chung SI, Park HJ: Serodiagnosis of Helicobacter pylori infection in Korean patients using enzyme-linked immunosorbent assay. J Immunoassay 1998, 19:251-270.

12. Kwon JW, Song YM, Sung J, Sohn Y, Cho Sl: Varying patterns of BMI increase in sex and birth cohorts of Korean adults. Obesity (Silver Spring) 2007, 15:277-282.

13. Shiota S, Murakami K, Fujioka T, Yamaoka Y: Population-based strategies for Helicobacter pylori-associated disease management: a Japanese perspective. Expert Rev Gastroenterol Hepatol 2010, 4:149-156.

14. Malaty HM, El-Kasabany A, Graham DY, Miller CC, Reddy SG, Srinivasan SR, Yamaoka Y, Berenson GS: Age at acquisition of Helicobacter pylori infection: a follow-up study from infancy to adulthood. Lancet 2002, 359:931-935.

15. Kim N, Lim SH, Lee KH, Kim JM, Cho SI, Jung HC, Song IS: Seroconversion of Helicobacter pylori in Korean male employees. Scand I Gastroenterol 2005, 40:1021-1027.

16. Perez-Perez Gl, Rothenbacher D, Brenner H: Epidemiology of Helicobacter pylori infection. Helicobacter 2004, 9(Suppl 1):1-6.

17. The EUROGAST Study Group: Epidemiology of, and risk factors for, Helicobacter pylori infection among 3194 asymptomatic subjects in 17 populations. Gut 1993, 34:1672-1676.

18. Moayyedi P, Axon AT, Feltbower R, Duffett S, Crocombe W, Braunholtz D, Richards IDG, Dowell AC, Forman D: Relation of adult lifestyle and socioeconomic factors to the prevalence of Helicobacter pylori infection. Int J Epidemiol 2002, 31:624-631.

19. Danesh J, Peto R: Risk factors for coronary heart disease and infection with Helicobacter pylori: meta-analysis of 18 studies. BMJ 1998, 316:1130-1132.

20. Oshima T, Ozono R, Yano Y, Oishi Y, Teragawa H, Higashi Y, Yoshizumi M, Kambe M: Association of Helicobacter pylori infection with systemic inflammation and endothelial dysfunction in healthy male subjects. J Am Coll Cardiol 2005, 45:1219-1222

21. Paximadas S, Pagoni ST, Kosmidis M, Tsarouchas X, Christou M, Chatziantonakis N, Papachilleos $P$ : The lipid profile in adults with negative or positive antibody Helicobacter pylori [abstract]. Atherosclerosis supplement 2005, 6:74.

22. Kucukazman M, Yavuz B, Sacikara M, Asilturk Z, Ata N, Ertugrul DT, Yalcin $A A$, Yenigum EC, Kizilca G, Okten H, Akin KO, Nazligul Y: The relationship between updated Sydney System score and LDL cholesterol levels in patients infected with Helicobacter pylori. Dig Dis Sci 2009, 54:604-607.

23. Laurila A, Bloigu A, Nayha S, Hassi H, Leinonen M, Saikku P: Association of Helicobacter pylori infection with elevated serum lipids. Atherosclerosis 1999, 142:207-210.

24. Majka J, Rog T, Konturek PC, Konturek SJ, Bielanski W, Kowalsky M, Szczudlik A: Influence of chronic Helicobacter pylori infection on ischemic cerebral stroke risk factors. Med Sci Moni 2002, 8:CR675-CR684.
25. Gallin Jl, Kaye D, O'Leary WM: Serum lipids in infection. N Engl J Med 1969, 281:1081-1086

26. Grunfeld C, Gulli R, Moser AH, Gavin LA, Feingold KR: Effect of tumor necrosis factor administration in vivo on lipoprotein lipase activity in various tissues of the rat. J Lipid Res 1989, 30:579-585.

27. Memon RA, Grunfeld C, Moser AH, Feingold KR: Tumor necrosis factor mediates the effects of endotoxin on cholesterol and triglyceride metabolism in mice. Endocrinology 1993, 132:2246-2253.

doi:10.1186/1471-230X-13-104

Cite this article as: Lim et al:: Prevalence and risk factors of Helicobacter pylori infection in Korea: Nationwide multicenter study over 13 years. BMC Gastroenterology 2013 13:104.

\section{Submit your next manuscript to BioMed Central and take full advantage of:}

- Convenient online submission

- Thorough peer review

- No space constraints or color figure charges

- Immediate publication on acceptance

- Inclusion in PubMed, CAS, Scopus and Google Scholar

- Research which is freely available for redistribution 